\title{
VEGF-C and TGF- $\beta$ reciprocally regulate mesenchymal stem cell commitment to differentiation into lymphatic endothelial or osteoblastic phenotypes
}

\author{
YASUYUKI IGARASHI $^{1,2^{*}}$, NAOYUKI CHOSA ${ }^{1 *}$, SHUNSUKE SAWADA $^{3,4}$, \\ HISATOMO KONDO $^{2}$, TAKASHI YAEGASHI ${ }^{3}$ and AKIRA ISHISAKI ${ }^{1}$ \\ ${ }^{1}$ Division of Cellular Biosignal Sciences, Department of Biochemistry, Iwate Medical University, Yahaba, \\ Iwate 028-3694; ${ }^{2}$ Department of Prosthodontics and Oral Implantology, and ${ }^{3}$ Division of Periodontology, \\ Department of Conservative Dentistry, Iwate Medical University School of Dentistry, Morioka, Iwate 020-8505; \\ ${ }^{4}$ Department of Otolaryngology, Dentistry and Oral Surgery, Kansai Medical University, Hirakata, Osaka 573-1010, Japan
}

Received September 17, 2015; Accepted February 12, 2016

DOI: $10.3892 /$ ijmm.2016.2502

\begin{abstract}
The direction of mesenchymal stem cell (MSC) differentiation is regulated by stimulation with various growth factors and cytokines. We recently established MSC lines, [transforming growth factor- $\beta$ (TGF- $\beta$ )-responsive SG-2 cells, bone morphogenetic protein (BMP)-responsive SG-3 cells, and TGF- $\beta$ /BMP-non-responsive SG-5 cells], derived from the bone marrow of green fluorescent protein-transgenic mice. In this study, to compare gene expression profiles in these MSC lines, we used DNA microarray analysis to characterize the specific gene expression profiles observed in the TGF- $\beta$ responsive SG-2 cells. Among the genes that were highly expressed in the SG-2 cells, we focused on vascular endothelial growth factor (VEGF) receptor 3 (VEGFR3), the gene product of FMS-like tyrosine kinase 4 (Flt4). We found that VEGF-C, a specific ligand of VEGFR3, significantly induced the cell proliferative activity, migratory ability (as shown by Transwell migration assay), as well as the phosphorylation of extracellular signal-regulated kinase (ERK)1/2 in the SG-2 cells. Additionally, VEGF-C significantly increased the expression of prospero homeobox 1 (Proxl) and lymphatic vessel endothelial hyaluronan receptor 1 (Lyvel), which are lymphatic endothelial cell markers, and decreased the expression of osteogenic differentiation marker genes in these cells. By contrast, TGF- $\beta$
\end{abstract}

Correspondence to: Dr Naoyuki Chosa, Division of Cellular Biosignal Sciences, Department of Biochemistry, Iwate Medical University, 2-1-1 Nshitokuta, Yahaba, Iwate 028-3694, Japan E-mail: nchosa@iwate-med.ac.jp

*Contributed equally

Key words: mesenchymal stem cells, lymphatic endothelial cells, vascular endothelial growth factor receptor 3, vascular endothelial growth factor C, p44/42 mitogen-activated protein kinase significantly increased the expression of early-phase osteogenic differentiation marker genes in the SG-2 cells and markedly decreased the expression of lymphatic endothelial cell markers. The findings of our study strongly suggest the following: i) that VEGF-C promotes the proliferative activity and migratory ability of MSCs; and ii) VEGF-C and TGF- $\beta$ reciprocally regulate MSC commitment to differentiation into lymphatic endothelial or osteoblastic phenotypes, respectively. Our findings provide new insight into the molecular mechanisms underlying the regenerative ability of MSCs.

\section{Introduction}

Mesenchymal stem cells (MSCs) were first derived from bone marrow and are characterized by their self-renewal ability and their capacity to develop into various mesenchymal tissue cells (1-3). Much of this differentiation process depends on the ability of the MSCs to proliferate and differentiate under the influence of various growth factors and cytokines (4-7). For example, the role of growth factors in bone repair is widely recognized, particularly with regard to bone morphogenetic protein (BMP), fibroblast growth factor (FGF), platelet-derived growth factor (PDGF), vascular endothelial growth factor (VEGF), insulin-like growth factor-I (IGF-I) and transforming growth factor- $\beta$ (TGF- $\beta$ ) $(8,9)$. In a recent study of ours, we demonstrated that PDGF-induced phosphoinositide 3-kinase (PI3K)-mediated signaling promoted the TGF- $\beta$-induced osteogenic differentiation of MSCs in a TGF- $\beta$-activated extracellular signal-regulated kinase (ERK) kinase-dependent manner (10). In a another recent study, we demonstrated that MSCs-secreted protein, scrapie responsive gene-1 (SCRG1), and its receptor bone marrow stromal cell antigen-1 (BST1), which played important roles in the maintenance of stemness and in the suppression of the osteogenic differentiation of MSCs (11).

VEGF, an important growth factor for bone repair, regulates numerous cellular events associated with angiogenesis and vasculogenesis, such as tissue remodeling during embryonic development and in adults (12). The mammalian VEGF 
signaling pathway consists of 5 glycoprotein ligands from the VEGF family (VEGF-A,-B, -C, -D and placental growth factor), 3 transmembrane receptors [VEGF receptor (VEGFR)1, VEGFR2 and VEGFR3] and 2 co-receptors (neuropilin-1 and -2) (13-22). VEGF-A binding to VEGFR2 is believed to be the key signaling pathway mediating angiogenesis $(14,23)$. VEGF-A enhances proliferation and survival, promotes cell migration, increases vascular permeability, and alters gene expression in endothelial cells $(13,14)$. VEGF-B binding to VEGFR1 promotes the survival of endothelial cells, pericytes, and smooth muscle cells and upregulates the expression of prosurvival genes (24). VEGF-C and VEGF-D bind to the receptors, VEGFR2 and VEGFR3 (22). VEGF-C expression has been shown to be associated with advanced metastasis in colorectal cancer (25) and to play a role in lymphangiogenesis and/or metastasis to lymph nodes in multiple types of cancer, including colorectal (26) and breast cancer $(27,28)$. VEGF-D is also involved in lymphangiogenesis and lymphatic metastasis $(29,30)$. On the other hand, in contrast to the well-studied VEGF signaling in endothelial cells, the VEGF signaling pathways in cells involved in bone repair, such as MSCs and osteoblasts, remains less well known (31). Osteoblasts express VEGFR1, VEGFR2 and the co-receptor, neuropilin (32). The expression of VEGF and its receptors in differentiating osteoblasts has been detected in cultured cells $(32,33)$, and an in vitro cell culture study suggested a role for VEGFR2 in both osteoblast differentiation and survival (34).

In a recent study of ours, we established 3 MSC lines (SG-2, $\mathrm{SG}-3$, and SG-5) derived from the bone marrow of green fluorescent protein (GFP)-transgenic mice (35). These cell lines clearly expressed the mouse MSC markers, stem cells antigen-1 (Sca-1) and CD44, and the SG-2 and SG-5 cells retained their potential for osteogenic and adipogenic differentiation. In addition, we examined the reactions of the TGF- $\beta$ superfamily in these MSC lines. The analysis of cytokine and cytokine receptor expression in these MSC lines revealed that $\mathrm{BMP}$ receptor $1 \mathrm{~B}$ was most strongly expressed in the SG-3 cells, which underwent osteogenesis in response to BMP. TGF- $\beta$ receptor II was more strongly expressed in the SG-3 and SG-5 cells. However, we unexpectedly noted that the phosphorylation of Smad2, a major transcription factor, was induced by TGF- $\beta 1$ in the SG- 2 cells, but not in the SG-3 or SG-5 cells. These findings demonstrated the establishment of TGF- $\beta$-responsive SG-2 MSCs, BMP-responsive SG-3 MSCs, and TGF- $\beta$ /BMP-non-responsive SG-5 MSCs.

In the present study, we focused on membrane proteins that are expressed specifically in SG-2 cells in order to facilitate the sorting and identification of the MSCs. VEGFR3, the gene product of FMS-like tyrosine kinase 4 (Flt4), was strongly expressed only in the SG-2 cells, but not in the SG-3 and SG-5 cells. Our findings demonstrate the role of VEGF-C, a specific ligand of VEGFR3, in the regenerative ability of the mouse MSC line, TGF- $\beta$-responsive SG- 2 cells.

\section{Materials and methods}

Mouse MSC lines. In a recent study of ours, we described the establishment process and culture method for all MSC lines derived from the bone marrow of GFP-transgenic mice: TGF- $\beta$-responsive SG-2, BMP-responsive SG-3 and TGF- $\beta$ /
BMP-non-responsive SG-5 cells (35). These cell lines were cultured in Dulbecco's modified Eagle's medium (DMEM; Sigma-Aldrich, St. Louis, MO, USA) supplemented with $10 \%$ fetal bovine serum (FBS; HyClone, GE Healthcare Life Sciences, Logan, UT, USA, Logan, UT, USA) at $37^{\circ} \mathrm{C}$ under hypoxic conditions $\left(5 \% \mathrm{O}_{2}, 5 \% \mathrm{CO}_{2}\right.$ and $\left.90 \% \mathrm{~N}_{2}\right)$.

DNA microarray analysis. Whole genome expression was analyzed for the bone-marrow derived SG-2, SG-3 and SG-5 MSC lines. Total RNA was extracted using ISOGEN reagent (Nippon Gene Co., Ltd., Tokyo, Japan). Filgen, Inc. (Nagoya, Japan) performed the DNA microarray analyses, including reverse transcription labeling, microarray hybridization, scanning and raw data analyses. For hybridization, 3 GeneChip Mouse Gene 2.0 ST arrays (Affymetrix, Santa Clara, CA, USA) were used. These analyses were conducted by the Research Institute of Bio-System Informatics (Tohoku Chemical Co., Ltd., Morioka, Japan).

Flow cytometry. Almost confluent SG-2, SG-3 and SG-5 cells $\left(1.0 \times 10^{5}\right)$ were suspended in ice-cold phosphatebuffered saline (PBS) containing $0.5 \%$ FBS and 2 mM EDTA. The cells were incubated with phycoerythrin (PE)-conjugated anti-mouse VEGFR3 (CD310) antibody (1:10, clone AFL4, \#130-102-216; Miltenyi Biotec, Bergisch Gladbach, Germany) for $1 \mathrm{~h}$ at $4^{\circ} \mathrm{C}$ in the dark. Acquisition was performed with an EPICS XL ADC system (Beckman Coulter, Inc., Brea, CA, USA).

Western blot analysis. The SG-2, SG-3 and SG-5 cells were serum-starved overnight and stimulated with $10 \mathrm{ng} / \mathrm{ml}$ VEGF-C (R\&D Systems, Inc., Minneapolis, MN, USA) for $1 \mathrm{~h}$ at $37^{\circ} \mathrm{C}$ under hypoxic conditions. The cells were washed twice with ice-cold PBS and then lysed in RIPA buffer (50 mM Tris- $\mathrm{HCl}, \mathrm{pH} 7.2,150 \mathrm{mM} \mathrm{NaCl}, 1 \% \mathrm{NP}-40$, $0.5 \%$ sodium deoxycholate and $0.1 \%$ SDS) containing protease and phosphatase inhibitor cocktails (Sigma-Aldrich). Protein content was measured using BCA reagent (Pierce/ Thermo Fisher Scientific, Waltham, MA, USA). Samples containing equal amounts of protein were separated using $12.5 \%$ SDS-polyacrylamide gel electrophoresis and transferred to a polyvinylidene difluoride membrane (Merck Millipore, Darmstadt, Germany). After blocking with 5\% non-fat dry milk in T-TBS (50 mM Tris- $\mathrm{HCl}, \mathrm{pH} 7.2,150 \mathrm{mM} \mathrm{NaCl}$ and $0.1 \%$ Tween-20), the membrane was incubated with primary anti-Akt (\#9272), anti-phospho-Akt (Ser473) [phosphorylated (p-)Akt; \#9271], anti-p44/42 mitogen-activated protein kinase (MAPK; ERK1/2; \#9102), anti-phospho-p44/42 MAPK (Thr202/Tyr204) (p-ERK1/2; \#9101), anti-p38 MAPK (p38; \#9212), anti-phospho-p38 MAPK (T180/Y182) (p-p38; \#9211), anti-stress-activated protein kinase/c-Jun N-terminal kinase (SAPK/JNK) (JNK; \#9252) and anti-phospho-SAPK/JNK (Thr183/Tyr185) (p-JNK; \#9251) antibodies (all from Cell Signaling Technology, Danvers, MA, USA), and anti- $\beta$-actin (clone C4; Santa Cruz Biotechnology, Dallas, TX, USA) antibody as a loading control for normalization. The blots were incubated with an alkaline phosphatase-conjugated secondary antibody and developed using the BCIP/NBT membrane phosphatase substrate system (Kirkegaard \& Perry Laboratories, Gaithersburg, MD, USA). 
Table I. Primer sequences.

\begin{tabular}{|c|c|c|}
\hline Gene name & Symbol & Primer sequence $\left(5^{\prime} \rightarrow 3^{\prime}\right)$ \\
\hline Prospero homeobox 1 & Proxl & $\begin{array}{l}\text { Forward: CGCTTAGCATTGCTGTTGCTG } \\
\text { Reverse: GAGCCATTCCTGGGTGATGTC }\end{array}$ \\
\hline Lymphatic vessel endothelial hyaluronan receptor 1 & Lyve1 & $\begin{array}{l}\text { Forward: GAGCCATTCAAAGTACCAGGTCCTAA } \\
\text { Reverse: ACATGTGCCTGGTTCCAAAG }\end{array}$ \\
\hline Runt-related transcription factor 2 & Runx 2 & $\begin{array}{l}\text { Forward: GACGTGCCCAGGCGTATTTC } \\
\text { Reverse: AAGGTGGCTGGGTAGTGCATTC }\end{array}$ \\
\hline Alkaline phosphatase, liver/bone/kidney & Alpl & $\begin{array}{l}\text { Forward: ACACCTTGACTGTGGTTACTGCTGA } \\
\text { Reverse: CCTTGTAGCCAGGCCCGTTA }\end{array}$ \\
\hline Integrin-binding sialoprotein & $I b s p$ & $\begin{array}{l}\text { Forward: AGAACAATCCGTGCCACTCACTC } \\
\text { Reverse: AGTAGCGTGGCCGGTACTTAAAGA }\end{array}$ \\
\hline Bone gamma-carboxyglutamate (gla) protein & Bglap & $\begin{array}{l}\text { Forward: CGGCCCTGAGTCTGACAAA } \\
\text { Reverse: TCTGTAGGCGGTCTTTAAGCCATA }\end{array}$ \\
\hline Glyceraldehyde 3-phosphate dehydrogenase & Gapdh & $\begin{array}{l}\text { Forward: TGTGTCCGTCGTGGATCTGA } \\
\text { Reverse: TTGCTGTTGAAGTCGCAGGAG }\end{array}$ \\
\hline
\end{tabular}

Cell proliferation assay. Cell proliferation was analyzed using a colorimetric assay for cleavage of the tetrazolium salt WST-1 (Roche Diagnostics, Basel, Switzerland) by mitochondrial dehydrogenases in viable cells. The measured absorbance of the dye directly correlates with the number of metabolically active cells in the culture. The cells were cultured in 96-well plates (Nunc; Thermo Fisher Scientific) in growth medium with/without $10 \mathrm{ng} / \mathrm{ml}$ VEGF-C under hypoxic conditions. After 5 days, the cells were incubated for a further $1 \mathrm{~h}$ at $37^{\circ} \mathrm{C}$ with $100 \mu \mathrm{l}$ medium containing $10 \mu \mathrm{l}$ WST-1 reagent. The samples were shaken for $1 \mathrm{~min}$, and absorbance was measured at $450 \mathrm{~nm}$ using an MPR-A4i microplate reader (Tosoh Corp., Tokyo, Japan).

Transwell migration assay. The migration assay was performed as reported previously using Transwell cell culture inserts (BD Biosciences, Franklin Lakes, NJ, USA) that were $6.5 \mathrm{~mm}$ in diameter with $8-\mu \mathrm{m}$ pore filters (11). The cells $\left(5.0 \times 10^{4}\right)$ were suspended in $350 \mu \mathrm{l}$ serum-free DMEM containing $0.1 \% \mathrm{BSA}$ (Sigma-Aldrich) and seeded into the upper well; $600 \mu \mathrm{l}$ normal growth medium with/without $10 \mathrm{ng} / \mathrm{ml} \mathrm{VEGF-C} \mathrm{was} \mathrm{placed} \mathrm{in}$ the lower well of the Transwell plate. Following incubation for $15 \mathrm{~h}$ under hypoxic conditions, the cells that had not migrated from the upper side of the filter were scraped off with a cotton swab, and the filters were stained with the three-step stain set (Diff-Quik; Sysmex, Kobe, Japan). The number of cells that had migrated to the lower side of the filter was counted under a light microscope in 5 high-power fields (x400 magnification; Olympus IX70; Olympus Corp., Tokyo, Japan). The experiment was performed in triplicate.

Reverse transcription-quantitative polymerase chain reaction (RT-qPCR). The SG-2, SG-3 and SG-5 cells were stimulated with $10 \mathrm{ng} / \mathrm{ml} \mathrm{VEGF-C} \mathrm{(R \& D} \mathrm{Systems)} \mathrm{or} 5.0 \mathrm{ng} / \mathrm{ml}$ TGF- $\beta$ (Calbiochem, Merck Millipore). After 48 h, total RNA from each cell was isolated using ISOGEN reagent (Nippon Gene Co., Ltd.) according to the manufacturer's instructions. First-strand cDNA was synthesized from total RNA using the PrimeScript RT Reagent kit (Takara Bio, Otsu, Japan). RT-qPCR was performed on a Thermal Cycler Dice Real-Time system with SYBR Premix Ex Taq II (both from Takara Bio) and specific oligonucleotide primers (Table I) using a two-step cycle procedure (denaturation at $95^{\circ} \mathrm{C}$ for $5 \mathrm{sec}$, annealing and extension at $60^{\circ} \mathrm{C}$ for $30 \mathrm{sec}$ ) for 40 cycles. For each test run, cDNA derived from $50 \mathrm{ng}$ total RNA as a template and $0.4 \mu \mathrm{M}$ primer pair was used. mRNA expression was normalized to glyceraldehyde 3-phosphate dehydrogenase (Gapdh), and the relative amounts of each mRNA in each sample were calculated using the $\Delta \Delta \mathrm{Cq}$ method. The relative mRNA expression levels are expressed as fold increase or decrease relative to the control.

Statistical analysis. All experiments were repeated at least 3 times. Representative images or data are shown. The numerical data are presented as the means \pm standard deviation (SD). Differences between averages and percentages between control and tests were statistically analyzed using paired two-tailed Student's t-tests. A P-value $<0.05$ was considered to indicate a statistically significant difference.

\section{Results}

Higher expression of VEGFR3 in SG-2 cells. To identify the genes that modulate the regenerative ability of MSCs, we used DNA microarrays to characterize the specific gene expression profiles observed in the TGF- $\beta$-responsive SG- 2 cells. We identified 105 genes that were $\geq 10$-fold more strongly expressed in the SG-2 cells compared to the SG-3 and SG-5 cells (Table II). Among these genes, we focused on VEGFR3, the Flt4 gene product, since, as a cell surface antigen, it is useful for identifying and sorting MSCs from various tissues. The gene expression level of Flt4 in the SG-2 cells was more than 16.5- and 32.0-fold higher than that in the SG-3 and SG-5 cells, respectively. These results were further confirmed by flow cytometry (Fig. 1) and indicated that the SG-2 cells expressed higher levels of VEGFR3 on the cell surface than the SG-3 and SG-5 cells. 
Table II. Genes expressed $\geq 10$-fold stronger in the SG-2 cells compared to the SG-3 and SG-5 cells.

Fold change in SG-2

Symbol

Gene name

vs. SG-3

75.7

Thrb

Grhl2

Olfr 1497

Arhgap15

Hoxd11

Cfcl

Kcnq5

Scgb2b7

Fn3krp

Tcpl0a

Serpina6

Cym

Ppplr3fos

Syn3

Lypd6

Olfr 772

Olfr2

Zfp 92

Fam81b

Ssxbl

Vmn2r25

Olfr368

Arhgef4

Ill 1

Fpr-rs3

Cldn13

Trim43c

Caskin1

Commd7

Prom2

St6galnac3

Slco6c1

Nhlrc4

Chrd

Olfr 117

Igkv4-53

Ctag2

F2rl3

Купи

Spata22

Vmn1r191

Ctnndl

Vmn1r234

Zfp174

Dgat 216

Nudt12os

Zap70

Flt4

Hes3

Sema6d

Slc17a4

Tbx2

Wdr95

Fer 115
Thyroid hormone receptor beta

Grainyhead-like 2 (Drosophila)

Olfactory receptor 1497

Rho GTPase activating protein 15

Homeobox D11

Cripto, FRL-1, cryptic family 1

Potassium voltage-gated channel, subfamily Q, member 5

Secretoglobin, family 2B, member 7

Fructosamine 3 kinase related protein

T-complex protein 10a

Serine (or cysteine) peptidase inhibitor, clade A, member 6

Chymosin

Protein phosphatase 1 , regulatory subunit $3 \mathrm{~F}$, opposite strand

Synapsin III

LY6/PLAUR domain containing 6

Olfactory receptor 772

Olfactory receptor 2

Zinc finger protein 92

Family with sequence similarity 81 , member B

Synovial sarcoma, X member B, breakpoint 1

Vomeronasal 2, receptor 25

Olfactory receptor 368

Rho guanine nucleotide exchange factor (GEF) 4

Interleukin 21

Formyl peptide receptor, related sequence 3

Claudin 13

Tripartite motif-containing 43C

CASK interacting protein 1

COMM domain containing 7

Prominin 2

ST6 ( $\alpha$-N-acetyl-neuraminyl-2,3- $\beta$-galactosyl-1,3)-N-acetylgalactosaminide $\alpha-2,6$-sialyltransferase 3

Solute carrier organic anion transporter family, member $6 \mathrm{c} 1$

NHL repeat containing 4

Chordin

Olfactory receptor 117

Immunoglobulin $\kappa$ variable 4-53

Cancer/testis antigen 2

Coagulation factor II (thrombin) receptor-like 3

Kynureninase (L-kynurenine hydrolase)

Spermatogenesis associated 22

Vomeronasal 1 receptor 191

Catenin (cadherin associated protein), delta 1

Vomeronasal 1 receptor 234

Zinc finger protein 174

Diacylglycerol O-acyltransferase 2-like 6

Nudix (nucleoside diphosphate linked moiety X)-type

motif 12 , opposite strand

Zeta-chain (TCR) associated protein kinase

FMS-like tyrosine kinase 4

Hairy and enhancer of split 3 (Drosophila)

Sema domain, transmembrane domain (TM),

and cytoplasmic domain, (semaphorin) 6D

Solute carrier family 17 (sodium phosphate), member 4

T-box 2

WD40 repeat domain 95

Fer-1-like 5 (C. elegans)
72.9

69.6

66.5

57.5

56.2

53.5

50.6

55.4

43.5

46.0

40.4

39.2

69.7

38.3

38.6

38.4

26.5

38.1

37.4

36.7

35.9

31.8

35.7

34.8

34.4

35.1

34.4

34.1

33.5

32.6

30.4

29.8

21.6

31.0

26.3

28.8

28.9

28.4

27.2

27.1

26.0

26.2

26.4

25.7

25.3

25.3

16.5

24.8

15.8

16.9

24.0

22.7

22.4 vs. SG-5

58.4

56.5

53.1

51.4

44.1

43.8

41.5

39.0

36.2

41.6

35.0

30.3

30.6

22.7

30.4

29.7

29.4

43.1

28.8

28.6

28.7

28.2

30.9

27.8

27.1

27.0

26.6

26.3

25.3

25.4

25.8

23.6

23.7

33.8

22.5

25.3

22.9

22.6

21.2

21.2

21.2

20.5

19.8

19.5

19.7

19.6

19.1

32.0

19.3

33.9

29.5

18.1

17.6

17.8 
Table II. Continued.

\begin{tabular}{|c|c|c|c|}
\hline \multirow[b]{2}{*}{ Symbol } & \multirow[b]{2}{*}{ Gene name } & \multicolumn{2}{|c|}{ Fold change in SG-2 } \\
\hline & & vs. SG-3 & vs. SG-5 \\
\hline$G b x 2$ & Gastrulation brain homeobox 2 & 15.0 & 29.1 \\
\hline$C d 33$ & CD33 antigen & 22.4 & 17.6 \\
\hline Tdrd5 & Tudor domain containing 5 & 22.8 & 17.0 \\
\hline Lixl & Limb expression 1 homolog (chicken) & 21.4 & 16.7 \\
\hline Lgals4 & Lectin, galactose binding, soluble 4 & 21.5 & 16.2 \\
\hline Pip5k1b & Phosphatidylinositol-4-phosphate 5-kinase, type $1 \beta$ & 21.4 & 15.9 \\
\hline Gsdma2 & Gasdermin A2 & 21.3 & 15.9 \\
\hline Ifi27l2b & Interferon, $\alpha$-inducible protein 27 like 2 beta & 16.0 & 19.8 \\
\hline Zcchcl8 & Zinc finger, CCHC domain containing 18 & 17.2 & 17.8 \\
\hline Olfr384 & Olfactory receptor 384 & 19.5 & 15.5 \\
\hline Olfr 1123 & Olfactory receptor 1123 & 11.4 & 33.8 \\
\hline Myolsb & Myosin XVIIIb & 11.8 & 29.6 \\
\hline Ss 18 & Synovial sarcoma translocation, Chromosome 18 & 23.4 & 13.0 \\
\hline Plxna4os1 & Plexin A4, opposite strand 1 & 19.5 & 14.4 \\
\hline Fam115e & Family with sequence similarity 115 , member $\mathrm{E}$ & 19.1 & 14.5 \\
\hline Fbxl5 & F-box and leucine-rich repeat protein 5 & 13.7 & 20.1 \\
\hline Megflo & Multiple EGF-like-domains 10 & 18.5 & 14.3 \\
\hline Robo3 & Roundabout homolog 3 (Drosophila) & 18.3 & 14.3 \\
\hline $\operatorname{Igkv4-91}$ & Immunoglobulin kappa chain variable 4-91 & 18.3 & 14.2 \\
\hline Elavl3 & $\begin{array}{l}\text { ELAV (embryonic lethal, abnormal vision, } \\
\text { Drosophila)-like } 3 \text { (Hu antigen C) }\end{array}$ & 15.7 & 16.1 \\
\hline Slc17a8 & $\begin{array}{l}\text { Solute carrier family } 17 \text { (sodium-dependent inorganic } \\
\text { phosphate cotransporter), member } 8\end{array}$ & 11.7 & 24.4 \\
\hline Gpr39 & $\mathrm{G}$ protein-coupled receptor 39 & 15.7 & 15.8 \\
\hline Catsperl & Cation channel, sperm associated 1 & 18.3 & 13.6 \\
\hline Zscan $4 a$ & Zinc finger and SCAN domain containing 4A & 17.4 & 13.8 \\
\hline Ceacam14 & Carcinoembryonic antigen-related cell adhesion molecule 14 & 17.8 & 13.3 \\
\hline Acnatl & Acyl-coenzyme A amino acid N-acyltransferase 1 & 12.4 & 17.8 \\
\hline Arhgap26 & Rho GTPase activating protein 26 & 17.4 & 12.6 \\
\hline Olfr 1270 & Olfactory receptor 1270 & 16.6 & 13.0 \\
\hline Lrrc25 & Leucine rich repeat containing 25 & 11.4 & 19.1 \\
\hline Capsl & Calcyphosine-like & 16.5 & 12.5 \\
\hline Gnl2 & Guanine nucleotide binding protein-like 2 (nucleolar) & 16.1 & 12.8 \\
\hline Ctnna3 & Catenin (cadherin associated protein), alpha 3 & 16.4 & 12.6 \\
\hline $\operatorname{Itm} 2 a$ & Integral membrane protein $2 \mathrm{~A}$ & 16.4 & 12.4 \\
\hline Sema5b & $\begin{array}{l}\text { Sema domain, seven thrombospondin repeats (type } 1 \text { and } \\
\text { type } 1 \text {-like), transmembrane domain (TM) and } \\
\text { short cytoplasmic domain, (semaphorin) 5B }\end{array}$ & 20.5 & 10.6 \\
\hline$I l 17 c$ & Interleukin $17 \mathrm{C}$ & 15.7 & 12.2 \\
\hline Chrna9 & Cholinergic receptor, nicotinic, alpha polypeptide 9 & 15.4 & 12.1 \\
\hline Acapl & ArfGAP with coiled-coil, ankyrin repeat and PH domains 1 & 10.8 & 17.0 \\
\hline Spint 5 & Serine protease inhibitor, Kunitz type 5 & 15.1 & 11.4 \\
\hline$R a b 5 b$ & RAB5B, member RAS oncogene family & 12.5 & 13.3 \\
\hline Olfr1122 & Olfactory receptor 1122 & 10.5 & 16.4 \\
\hline Grm8 & Glutamate receptor, metabotropic 8 & 17.6 & 10.1 \\
\hline Igh-VJ558 & Immunoglobulin heavy chain (J558 family) & 14.4 & 11.2 \\
\hline Ptprzl & Protein tyrosine phosphatase, receptor type Z, polypeptide 1 & 14.4 & 11.1 \\
\hline Cd300lh & $\mathrm{CD} 300$ antigen-like family member $\mathrm{H}$ & 15.2 & 10.4 \\
\hline Mcoln 1 & Mucolipin 1 & 11.7 & 12.8 \\
\hline Olfr649 & Olfactory receptor 649 & 13.9 & 10.9 \\
\hline Tlr8 & Toll-like receptor 8 & 13.9 & 10.7 \\
\hline Mb21d1 & Mab-21 domain containing 1 & 10.8 & 13.2 \\
\hline Itgblbp2 & Integrin beta 1 binding protein 2 & 13.3 & 10.5 \\
\hline Defb28 & Defensin beta 28 & 13.3 & 10.4 \\
\hline Cypt 2 & Cysteine-rich perinuclear theca 2 & 13.4 & 10.3 \\
\hline
\end{tabular}




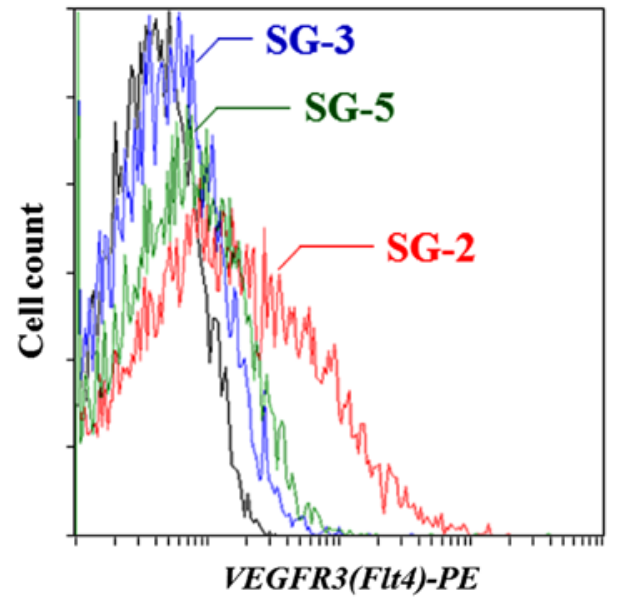

Figure 1. Vascular endothelial growth factor receptor 3 (VEGFR3) expression on the cell surface was detected in SG-2 cells. Cell surface expression of VEGFR3 was analyzed with a VEGFR3-specific antibody in SG-2 (red), SG-3 (blue) and SG-5 (green) cells and an isotype control IgG (black) using flow cytometry.
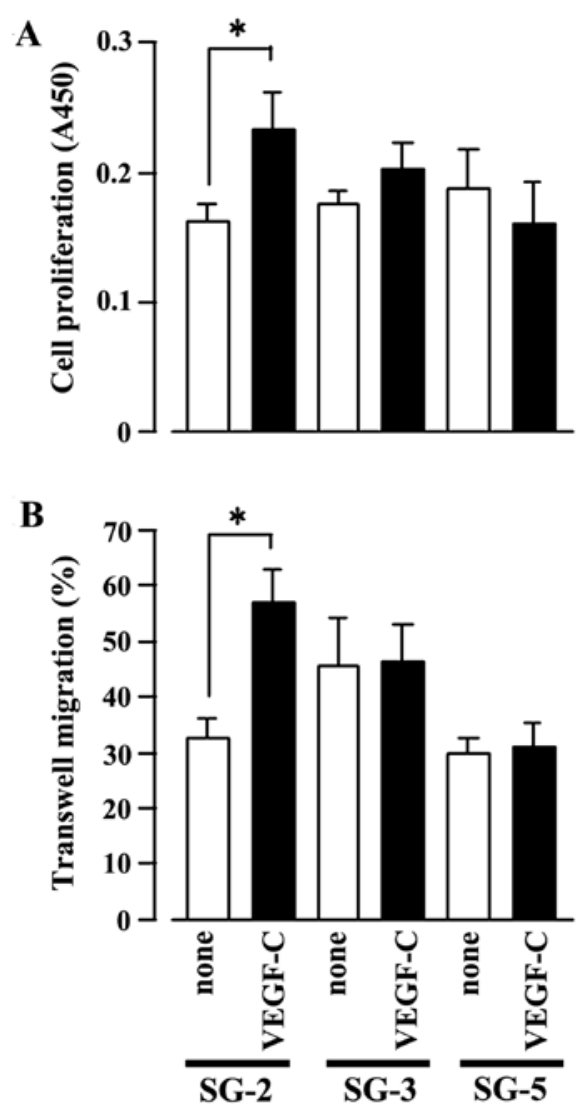

Figure 2. Cell proliferative activity and migratory ability increases with vascular endothelial growth factor-C (VEGF-C) stimulation in FMS-like tyrosine kinase 4 (Flt4)-positive SG-2 cells. (A) Cell proliferation assay for SG-2, SG-3 and SG-5 cells stimulated with (VEGF-C) or without (none) $10 \mathrm{ng} / \mathrm{ml} \mathrm{VEGF-C}$ measured as the absorbance at $450 \mathrm{~nm}$ (A450). (B) Transwell migration assay for SG-2, SG-3 and SG-5 cells. Cell numbers were counted in 5 fields under a light microscope. In (A) and (B), data are presented as the means \pm SD. ${ }^{*} \mathrm{p}<0.05$ vs. unstimulated control (none) within each cell line.

Promotion of the migratory ability and proliferative activity of $S G-2$ cells by VEGF-C. Subsequently, we examined the effects of

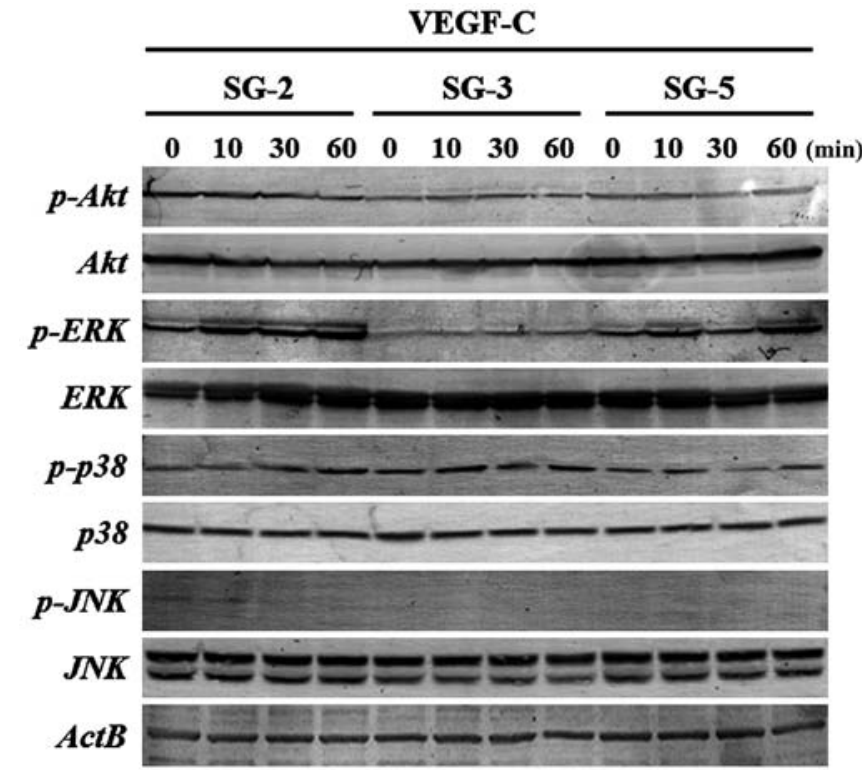

Figure 3. Extracellular signal-regulated kinase 1/2 (ERK1/2) phosphorylation is induced by vascular endothelial growth factor-C (VEGF-C) stimulation in FMS-like tyrosine kinase 4 (Flt4)-positive SG-2 cells. Phosphorylation levels were measured using western blot analysis in SG-2, SG-3 and SG-5 cells stimulated with $10 \mathrm{ng} / \mathrm{ml}$ VEGF-C.

VEGF-C, a specific ligand of VEGFR3, on the MSC lines (SG-2, SG-3 and SG-5). Indeed, VEGF-C significantly stimulated SG-2 cell proliferation (Fig. 2A) and cell migration (Fig. 2B), but had no effect on the SG-3 or SG-5 cells. These results strongly suggest that VEGF-C specifically promotes the proliferative activity and migratory ability of the SG-2 cells through VEGFR3.

Phosphorylation of ERK1/2 in SG-2 cells by stimulation with $V E G F-C$. To clarify the signaling pathways activated by VEGF-C in SG-2 cells, we evaluated the phosphorylation status of molecules in the PI3K/Akt- and MAPK-mediated pathways. ERK1/2 phosphorylation was markedly upregulated in the SG-2 cells upon VEGF-C stimulation, whereas that in the SG-3 and SG-5 cells was unaffected (Fig. 3). These results suggest that VEGF-C enhances the proliferative activity and migratory ability of the MSCs through the ERK1/2 pathway in Flt4-positive SG-2 cells.

Increase in the expression of lymphatic endothelial differentiation marker genes following stimulation of SG-2 cells with $V E G F-C$. The VEGF-C gene encodes a ligand for VEGFR3 that is expressed mainly in lymphatic endothelia (18). Furthermore, the VEGF-C/VEGFR3 pathway was the first critical pathway described for the development of the lymphatic vascular tree (36). As the SG-2 cells respond to both TGF- $\beta$ and VEGF-C, we examined the effects of TGF- $\beta$ or VEGF-C stimulation on their multi-differentiation potential. VEGF-C clearly and significantly increased the mRNA expression levels of the lymphatic endothelial cell markers, prospero homeobox 1 (Proxl) and lymphatic vessel endothelial hyaluronan receptor 1 (Lyvel) $(\mathrm{p}<0.01)$, in the SG-2 cells, whereas the levels were clearly and significantly decreased following stimulation of the cells with TGF- $\beta$ ( $p<0.05$; Fig. 4 A and B). We previously reported that TGF- $\beta$ promotes the osteogenic 
A

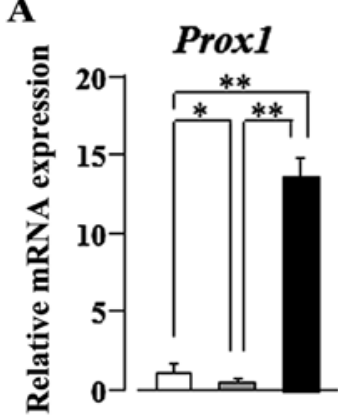

$\begin{array}{lll}\text { TGF- } \beta & - & + \\ \text { VEGF-C }- & - & +\end{array}$

C

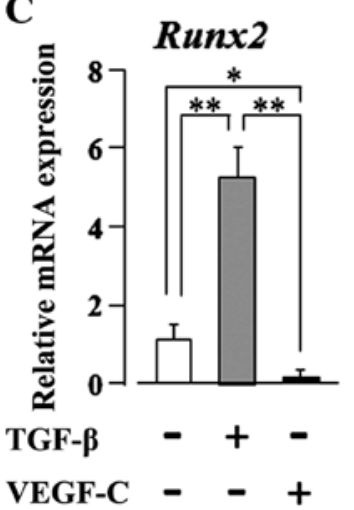

E

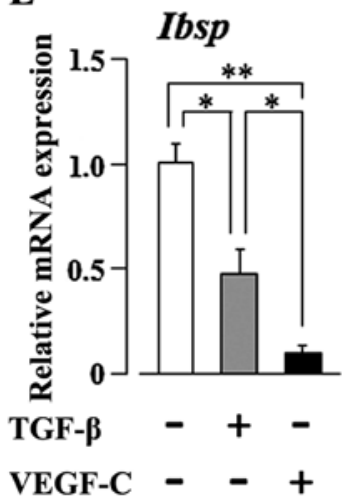

B

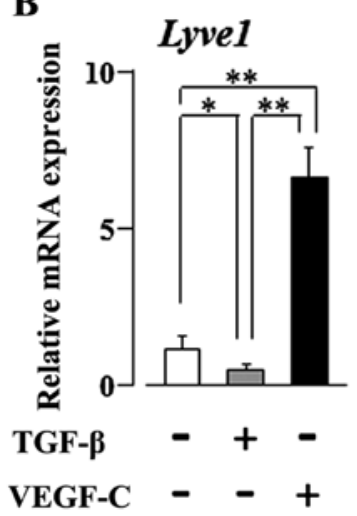

D

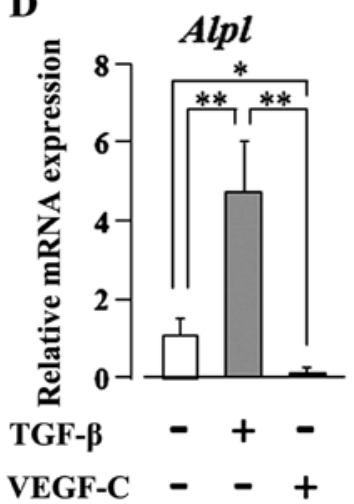

F

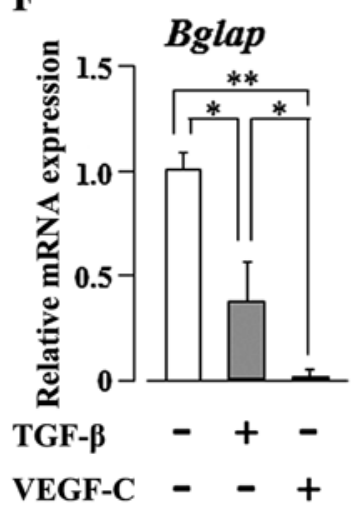

Figure 4. Vascular endothelial growth factor-C (VEGF-C) and transforming growth factor- $\beta$ (TGF- $\beta$ ) reciprocally regulate the commitment of mesenchymal stem cells (MSCs) to differentiation into lymphatic endothelial or osteoblastic phenotypes, respectively. RT-qPCR of (A) Prox1, (B) Lyve1, (C) Runx2, (D) Alpl, (E) Ibsp and (F) Bglap in SG-2 cells stimulated with $10 \mathrm{ng} / \mathrm{ml}$ VEGF-C or $5.0 \mathrm{ng} / \mathrm{ml}$ TGF- $\beta$. Reported values are normalized to Gapdh expression. The results are expressed as the fold change relative to the respective control. Data are presented as the means $\pm \mathrm{SD}$. ${ }^{*} \mathrm{p}<0.05,{ }^{* *} \mathrm{p}<0.01$.

differentiation of bone marrow-derived MSCs (10). Therefore, in this study, we further investigated the mRNA expression of osteogenic differentiation markers in the SG-2 cells following TGF- $\beta$ or VEGF-C stimulation. TGF- $\beta$ clearly and significantly increased the expression of the early-stage osteogenic differentiation marker genes, Runt-related transcription factor 2 (Runx2) and alkaline phosphatase, liver/bone/ kidney $(A l p l)(\mathrm{p}<0.01)$, in the SG-2 cells; by contrast, VEGF-C clearly and significantly decreased the expression of these

early-stage osteogenic differentiation markers ( $<<0.05$; Fig. 4C and D). Of note, TGF- $\beta$ unexpectedly decreased the expression of the late-stage osteogenic differentiation markers, integrin-binding sialoprotein (Ibsp) and bone gamma-carboxyglutamate (Gla) protein (Bglap) $(\mathrm{p}<0.05$; Fig. 4E and F). On the other hand, as expected, VEGF-C suppressed the expression of these late-stage differentiation markers $(p<0.01$; Fig. $4 \mathrm{E}$ and $F$ ). These results suggest that VEGF-C and TGF- $\beta$ reciprocally regulate the commitment of MSCs to differentiate into lymphatic endothelial or osteoblastic phenotypes, respectively. On the other hand, both TGF- $\beta$ and VEGF-C appear to suppress the final maturation of osteoblastic MSC differentiation during late-stage osteogenesis.

\section{Discussion}

As demonstrated in our previous study, the TGF- $\beta$-responsive, Flt4-positive SG-2 MSC line retained both osteogenic and adipogenic differentiation potentials (35). Herein, we focused on SG-2-specific membrane protein expression and identified high expression levels of VEGFR3, the Flt4 gene product (Table II and Fig. 1). Furthermore, we found that the VEGFR3-specific ligand, VEGF-C, significantly increased the proliferative activity and migratory ability of the SG-2 cells (Fig. 2). VEGF potently promotes angiogenesis and is indispensable for vascular development $(37,38)$, and the tyrosine kinase receptor, VEGFR2, is the primary transmitter of VEGF signals in endothelial cells $(39,40)$. The binding of VEGF-A to VEGFR2 activates downstream signaling, including the MAPK pathways $(41,42)$. Other VEGF family members and other signaling mediators affect and overlap with the function of VEGF-A $(22,43,44)$. VEGFR3 is activated by the VEGF homologues, VEGF-C and VEGF-D, which, when fully proteolytically processed, also stimulate VEGFR2 and induce the formation and activation of VEGFR2-VEGFR3 heterodimers $(36,45,46)$. Since in this study VEGF-C stimulation induced ERK1/2 phosphorylation in the SG-2 cells, the promotion of the migratory ability and proliferative activity of Flt4-positive MSCs appears to depend on the activation of the MAPK cascade (Fig. 3).

The VEGF-C/VEGFR3 pathway was the first critical pathway described for the development of the lymphatic vascular tree (36). It has been demonstrated that VEGFR3 expression starts during mouse embryonic day 8.5 in developing blood vessels, and VEGFR3-deficient embryos die at midgestation from defects in the remodeling of primary vascular networks (47). In adult tissues, VEGFR3 expression occurs mainly in lymphatic endothelial cells (47-50), and VEGFR3positive lymphatic vessels appear concurrently with blood vessels during wound healing, but regress rapidly (51). However, VEGFR3-expressing endothelial cells may also be found in the fenestrated capillaries of several adult organs, including the bone marrow, splenic and hepatic sinusoids, kidney glomeruli and endocrine glands (50). Notably, in human cancer, VEGFR3expressing vascular endothelial cells are detected in angiogenic capillaries $(52,53)$, and the inactivation of VEGFR3 signaling with blocking antibodies in nude mice has been shown to suppress tumor growth by inhibiting angiogenesis (54).

MSCs have been reported to home towards hypoxic microenvironments in vivo, and hypoxic tumor cells specifically 
recruit MSCs by activating survival pathways that facilitate tumor progression (55). Based on these findings, the results of our study suggest that Flt4-positive MSCs play an important role in tumor angiogenesis and lymphatic vessel formation. Previous studies have demonstrated the VEGF-mediated differentiation of lymphatic endothelial cells from bone marrow-derived MSCs $(56,57)$.

In this study, our results indicated that stimulation with VEGF-C increased the expression of lymphatic endothelial cell marker genes in Flt4-positive SG-2 cells (Fig. 4A and B). More interestingly, VEGF-C suppressed the expression of osteogenic differentiation marker genes (Fig. 4C and D). On the other hand, TGF- $\beta$ suppressed the lymphatic endothelial commitment of SC-2 cells (Fig. 4A and B). Thus, we concluded that VEGF-C and TGF- $\beta$ reciprocally regulate MSC commitment to differentiation into lymphatic endothelial or osteoblastic phenotypes, respectively. However, TGF- $\beta$ and VEGF-C both seem to suppress the maturation of osteoblastic MSC differentiation at the late stage of the osteogenic process, suggesting that additional cellular signals must be necessary for the progression of osteoblastic differentiation of some types of MSCs. In addition, VEGF-C positively regulated the migration and proliferation of the Flt4-positive SG-2 cells (Fig. 2). The migratory ability and the proliferative activity are necessary conditions of MSCs, suggesting the novel possibility that VEGF-C plays an important role in determining MSC characteristics.

Our findings provide new insight into the molecular mechanisms underlying the regenerative activity of MSCs. In future studies, we aim to determine whether these results are reproducible in vivo by transplanting GFP-expressing SG-2 cells into suitable animal experimental models to facilitate their discrimination from the surrounding donor cells.

\section{Acknowledgements}

The present study was supported in part by JSPS KAKENHI grant nos. 25463053 to N.C., 25893221 and 15K20633 to S.S., 26462932 to H.K. and 26670852 to A.I.; a Grant-in-Aid for Strategic Medical Science Research Centre from the Ministry of Education, Culture, Sports, Science and Technology of Japan, 2010-2014; and a grant from the Keiryokai Research Foundation grant no. 120 to N.C. and S.S., 2013.

\section{References}

1. Prockop DJ: Marrow stromal cells as stem cells for nonhematopoietic tissues. Science 276: 71-74, 1997.

2. Pittenger MF, Mackay AM, Beck SC, Jaiswal RK, Douglas R, Mosca JD, Moorman MA, Simonetti DW, Craig S and Marshak DR: Multilineage potential of adult human mesenchymal stem cells. Science 284: 143-147, 1999.

3. Docheva D, Popov C, Mutschler W and Schieker M: Human mesenchymal stem cells in contact with their environment: surface characteristics and the integrin system. J Cell Mol Med 11: 21-38, 2007.

4. Vidane AS, Zomer HD, Oliveira BM, Guimarães CF, Fernandes CB, Perecin F, Silva LA, Miglino MA, Meirelles FV and Ambrósio CE: Reproductive stem cell differentiation: extracellular matrix, tissue microenvironment, and growth factors direct the mesenchymal stem cell lineage commitment. Reprod Sci 20: 1137-1143, 2013.

5. Chen BY, Wang X, Chen LW and Luo ZJ: Molecular targeting regulation of proliferation and differentiation of the bone marrowderived mesenchymal stem cells or mesenchymal stromal cells. Curr Drug Targets 13: 561-571, 2012.
6. Soleymaninejadian E, Pramanik K and Samadian E: Immunomodulatory properties of mesenchymal stem cells: cytokines and factors. Am J Reprod Immunol 67: 1-8, 2012.

7. Chau JF, Leong WF and Li B: Signaling pathways governing osteoblast proliferation, differentiation and function. Histol Histopathol 24: 1593-1606, 2009.

8. Pountos I, Georgouli T, Henshaw K, Bird H, Jones E and Giannoudis PV: The effect of bone morphogenetic protein-2, bone morphogenetic protein-7, parathyroid hormone, and platelet-derived growth factor on the proliferation and osteogenic differentiation of mesenchymal stem cells derived from osteoporotic bone. J Orthop Trauma 24: 552-556, 2010.

9. Hughes FJ, Turner W, Belibasakis G and Martuscelli G: Effects of growth factors and cytokines on osteoblast differentiation. Periodontol 2000 41: 48-72, 2006.

10. Yokota J, Chosa N, Sawada S, Okubo N, Takahashi N, Hasegawa T, Kondo $\mathrm{H}$ and Ishisaki A: PDGF-induced PI3K-mediated signaling enhances the TGF- $\beta$-induced osteogenic differentiation of human mesenchymal stem cells in a TGF- $\beta$-activated MEK-dependent manner. Int J Mol Med 33: 534-542, 2014.

11. Aomatsu E, Takahashi N, Sawada S, Okubo N, Hasegawa T, Taira M, Miura H, Ishisaki A and Chosa N: Novel SCRG1/BST1 axis regulates self-renewal, migration, and osteogenic differentiation potential in mesenchymal stem cells. Sci Rep 4: 3652, 2014.

12. Ferrara N: Vascular endothelial growth factor: basic science and clinical progress. Endocr Rev 25: 581-611, 2004.

13. Ellis LM and Hicklin DJ: VEGF-targeted therapy: mechanisms of anti-tumour activity. Nat Rev Cancer 8: 579-591, 2008.

14. Dvorak HF: Vascular permeability factor/vascular endothelial growth factor: a critical cytokine in tumor angiogenesis and a potential target for diagnosis and therapy. J Clin Oncol 20: 4368-4380, 2002.

15. Orlandini M, Marconcini L, Ferruzzi R and Oliviero S: Identification of a c-fos-induced gene that is related to the platelet-derived growth factor/vascular endothelial growth factor family. Proc Natl Acad Sci USA 93: 11675-11680, 1996.

16. Roche PA and Cresswell P: Proteolysis of the class II-associated invariant chain generates a peptide binding site in intracellular HLA-DR molecules. Proc Natl Acad Sci USA 88: 3150-3154, 1991.

17. Olofsson B, Pajusola K, Kaipainen A, von Euler G, Joukov V, Saksela O, Orpana A, Pettersson RF, Alitalo K and Eriksson U: Vascular endothelial growth factor B, a novel growth factor for endothelial cells. Proc Natl Acad Sci USA 93: 2576-2581, 1996.

18. Joukov V, Pajusola K, Kaipainen A, Chilov D, Lahtinen I, Kukk E, Saksela O, Kalkkinen N and Alitalo K: A novel vascular endothelial growth factor, VEGF-C, is a ligand for the Flt4 (VEGFR-3) and KDR (VEGFR-2) receptor tyrosine kinases. EMBO J 15: 1751, 1996.

19. Soker S, Takashima S, Miao HQ, Neufeld G and Klagsbrun M: Neuropilin-1 is expressed by endothelial and tumor cells as an isoform-specific receptor for vascular endothelial growth factor. Cell 92: 735-745, 1998.

20. Migdal M, Huppertz B, Tessler S, Comforti A, Shibuya M, Reich R, Baumann H and Neufeld G: Neuropilin-1 is a placenta growth factor-2 receptor. J Biol Chem 273: 22272-22278, 1998.

21. Neufeld G, Kessler O and Herzog Y: The interaction of Neuropilin-1 and Neuropilin-2 with tyrosine-kinase receptors for VEGF. Adv Exp Med Biol 515: 81-90, 2002.

22. Cao Y: Positive and negative modulation of angiogenesis by VEGFR1 ligands. Sci Signal 2: re1, 2009.

23. Kerbel RS: Tumor angiogenesis. N Engl J Med 358: 2039-2049, 2008.

24. Zhang F, Tang Z, Hou X, Lennartsson J, Li Y, Koch AW, Scotney P, Lee C, Arjunan P, Dong L, et al: VEGF-B is dispensable for blood vessel growth but critical for their survival, and VEGF-B targeting inhibits pathological angiogenesis. Proc Natl Acad Sci USA 106: 6152-6157, 2009.

25. Hanrahan V, Currie MJ, Gunningham SP, Morrin HR, Scott PA, Robinson BA and Fox SB: The angiogenic switch for vascular endothelial growth factor (VEGF)-A, VEGF-B, VEGF-C, and VEGF-D in the adenoma-carcinoma sequence during colorectal cancer progression. J Pathol 200: 183-194, 2003.

26. Wang TB, Chen ZG, Wei XQ, Wei B and Dong WG: Serum vascular endothelial growth factor- $\mathrm{C}$ and lymphoangiogenesis are associated with the lymph node metastasis and prognosis of patients with colorectal cancer. ANZ J Surg 81: 694-699, 2011.

27. Skobe M, Hawighorst T, Jackson DG, Prevo R, Janes L, Velasco P, Riccardi L, Alitalo K, Claffey K and Detmar M: Induction of tumor lymphangiogenesis by VEGF-C promotes breast cancer metastasis. Nat Med 7: 192-198, 2001. 
28. Wu QW, She HQ, Liang J, Huang YF, Yang QM, Yang QL and Zhang ZM: Expression and clinical significance of extracellular matrix protein 1 and vascular endothelial growth factor- $\mathrm{C}$ in lymphatic metastasis of human breast cancer. BMC Cancer 12 : 47, 2012 .

29. Karnezis T, Shayan R, Caesar C, Roufail S, Harris NC, Ardipradja K, Zhang YF, Williams SP, Farnsworth RH, Chai MG, et al: VEGF-D promotes tumor metastasis by regulating prostaglandins produced by the collecting lymphatic endothelium. Cancer Cell 21: 181-195, 2012.

30. Stacker SA, Caesar C, Baldwin ME, Thornton GE, Williams RA Prevo R, Jackson DG, Nishikawa S, Kubo H and Achen MG: VEGF-D promotes the metastatic spread of tumor cells via the lymphatics. Nat Med 7: 186-191,2001.

31. Liu Y and Olsen BR: Distinct VEGF functions during bone development and homeostasis. Arch Immunol Ther Exp (Warsz) 62: 363-368, 2014

32. Deckers MM, Karperien M, van der Bent C, Yamashita T, Papapoulos SE and Löwik CW: Expression of vascular endothelial growth factors and their receptors during osteoblast differentiation. Endocrinology 141: 1667-1674, 2000.

33. Zelzer E, McLean W, Ng YS, Fukai N, Reginato AM, Lovejoy S, D'Amore PA and Olsen BR: Skeletal defects in VEGF(120/120) mice reveal multiple roles for VEGF in skeletogenesis. Development 129: 1893-1904, 2002

34. Alonso V, de Gortázar AR, Ardura JA, Andrade-Zapata I, Alvarez-Arroyo MV and Esbrit P: Parathyroid hormone-related protein (107-139) increases human osteoblastic cell survival by activation of vascular endothelial growth factor receptor-2. J Cell Physiol 217: 717-727, 2008.

35. Sawada S, Chosa N, Takizawa N, Yokota J, Igarashi Y, Tomoda K, Kondo H, Yaegashi T and Ishisaki A: Establishment of mesenchymal stem cell lines derived from the bone marrow of GFP-transgenic mice exhibiting diversity in intracellular TGF- $\beta$ and BMP signaling. Mol Med Rep 13: 2023-2031, 2016.

36. Tammela $\mathrm{T}$ and Alitalo $\mathrm{K}$ : Lymphangiogenesis: molecular mechanisms and future promise. Cell 140: 460-476, 2010

37. Ferrara N, Carver-Moore K, Chen H, Dowd M, Lu L, O'Shea KS, Powell-Braxton L, Hillan KJ and Moore MW: Heterozygous embryonic lethality induced by targeted inactivation of the VEGF gene. Nature 380: 439-442, 1996.

38. Carmeliet P, Mackman N, Moons L, Luther T, Gressens P, Van Vlaenderen I, Demunck H, Kasper M, Breier G Evrard P, et al: Role of tissue factor in embryonic blood vessel development. Nature 383: 73-75, 1996.

39. Shalaby F, Rossant J, Yamaguchi TP, Gertsenstein M, Wu XF, Breitman ML and Schuh AC: Failure of blood-island formation and vasculogenesis in Flk-1-deficient mice. Nature 376: 62-66, 1995.

40. Gille H, Kowalski J, Li B, LeCouter J, Moffat B, Zioncheck TF, Pelletier N and Ferrara N: Analysis of biological effects and signaling properties of Flt-1 (VEGFR-1) and KDR (VEGFR-2) A reassessment using novel receptor-specific vascular endothelial growth factor mutants. J Biol Chem 276: 3222-3230, 2001.

41. Takahashi T, Ueno $H$ and Shibuya M: VEGF activates protein kinase C-dependent, but Ras-independent Raf-MEK-MAP kinase pathway for DNA synthesis in primary endothelial cells. Oncogene 18: 2221-2230, 1999.

42. Meadows KN, Bryant P and Pumiglia K: Vascular endothelial growth factor induction of the angiogenic phenotype requires Ras activation. J Biol Chem 276: 49289-49298, 2001.

43. Huang H, Bhat A, Woodnutt G and Lappe R: Targeting the ANGPT-TIE2 pathway in malignancy. Nat Rev Cancer 10 $575-585,2010$
44. Weis SM and Cheresh DA: $\alpha \mathrm{V}$ integrins in angiogenesis and cancer. Cold Spring Harb Perspect Med 1: a006478, 2011.

45. Dixelius J, Makinen T, Wirzenius M, Karkkainen MJ, Wernstedt C, Alitalo K and Claesson-Welsh L: Ligand-induced vascular endothelial growth factor receptor-3 (VEGFR-3) heterodimerization with VEGFR-2 in primary lymphatic endothelial cells regulates tyrosine phosphorylation sites. J Biol Chem 278: 40973-40979, 2003

46. Nilsson I, Bahram F, Li X, Gualandi L, Koch S, Jarvius M, Söderberg O, Anisimov A, Kholová I, Pytowski B, et al: VEGF receptor $2 /-3$ heterodimers detected in situ by proximity ligation on angiogenic sprouts. EMBO J 29: 1377-1388, 2010.

47. Dumont DJ, Jussila L, Taipale J, Lymboussaki A, Mustonen T, Pajusola K, Breitman M and Alitalo K: Cardiovascular failure in mouse embryos deficient in VEGF receptor-3. Science 282: 946-949, 1998

48. Kaipainen A, Korhonen J, Mustonen T, van Hinsbergh VW, Fang GH, Dumont D, Breitman M and Alitalo K: Expression of the fms-like tyrosine kinase 4 gene becomes restricted to lymphatic endothelium during development. Proc Natl Acad Sci USA 92: 3566-3570, 1995.

49. Jussila L, Valtola R, Partanen TA, Salven P, Heikkilä P, Matikainen MT, Renkonen R, Kaipainen A, Detmar M, Tschachler E, et al: Lymphatic endothelium and Kaposi's sarcoma spindle cells detected by antibodies against the vascular endothelial growth factor receptor-3. Cancer Res 58: 1599-1604, 1998.

50. Partanen TA, Arola J, Saaristo A, Jussila L, Ora A, Miettinen M, Stacker SA, Achen MG and Alitalo K: VEGF-C and VEGF-D expression in neuroendocrine cells and their receptor, VEGFR-3, in fenestrated blood vessels in human tissues. FASEB J 14: 2087-2096, 2000.

51. Paavonen K, Puolakkainen P, Jussila L, Jahkola T and Alitalo K: Vascular endothelial growth factor receptor-3 in lymphangiogenesis in wound healing. Am J Pathol 156: 1499-1504, 2000

52. Valtola R, Salven P, Heikkilä P, Taipale J, Joensuu H, Rehn M, Pihlajaniemi T, Weich H, deWaal R and Alitalo K: VEGFR-3 and its ligand VEGF-C are associated with angiogenesis in breast cancer. Am J Pathol 154: 1381-1390, 1999.

53. Partanen TA, Alitalo K and Miettinen M: Lack of lymphatic vascular specificity of vascular endothelial growth factor receptor 3 in 185 vascular tumors. Cancer 86: 2406-2412, 1999.

54. Kubo H, Fujiwara T, Jussila L, Hashi H, Ogawa M, Shimizu K, Awane M, Sakai Y, Takabayashi A, Alitalo K, et al: Involvement of vascular endothelial growth factor receptor-3 in maintenance of integrity of endothelial cell lining during tumor angiogenesis. Blood 96: 546-553, 2000.

55. Rattigan Y, Hsu JM, Mishra PJ, Glod J and Banerjee D: Interleukin 6 mediated recruitment of mesenchymal stem cells to the hypoxic tumor milieu. Exp Cell Res 316: 3417-3424, 2010.

56. Wei L, Liu Y, Chen G, Fang Y, Song X, Dong P, Gao J, Liu R, Ding Z, Bi Y and Liu Z: Differentiation of lymphatic endothelial cells from bone marrow mesenchymal stem cells with VEGFs. Lymphology 45: 177-187, 2012.

57. Zhan J, Li Y, Yu J, Zhao Y, Cao W, Ma J, Sun X, Sun L, Qian H, $\mathrm{Zhu} \mathrm{W}$ and $\mathrm{Xu} \mathrm{W}$ : Culture medium of bone marrow-derived human mesenchymal stem cells effects lymphatic endothelial cells and tumor lymph vessel formation. Oncol Lett 9: 1221-1226, 2015. 